\title{
Sucrose/bovine serum albumin mediated biomimetic crystallization of calcium carbonate
}

\author{
CHENG-LI YAO, ${ }^{1, *}$ WANG-HUA XU, ${ }^{2}$ AI-MIN DING ${ }^{1}$ and JIN-MAO ZHU ${ }^{1}$ \\ ${ }^{1}$ Department of Chemistry, Hefei Teachers College, Hefei, Anhui 230061, China \\ ${ }^{2}$ Department of Chemistry, Anqing Teachers College, Anqing, Anhui 246011, China \\ e-mail: yaochengli@hftc.edu.cn
}

MS received 19 July 2008; revised 2 September 2008

\begin{abstract}
To understand the role of the sucrose/bovine serum albumin system in the biomineralization process, we have tested the influence of different concentration of the sucrose/bovine serum albumin (BSA) on calcium carbonate $\left(\mathrm{CaCO}_{3}\right)$ precipitation. The $\mathrm{CaCO}_{3}$ crystals were characterized by scanning electron microscope (SEM), Fourier transform infrared spectrograph (FT-IR) and powder X-ray diffractometry (XRD). The possible formation mechanism of $\mathrm{CaCO}_{3}$ in the sucrose/bovine serum albumin system was discussed.
\end{abstract}

Keywords. Bovine serum albumin; sucrose; calcium carbonate; biomineralization; mechanism.

\section{Introduction}

A widespread phenomenon in the biological world is biomineralization, a process by which organisms precipitate inorganic minerals. Over 60 biominerals are known, the most abundant of which are calcium carbonates, silica and iron oxides. These biominerals are organized hierarchically and ordered at many length scales that reflect remarkable physical characteristics. Mineralization in biological systems is an elegant and structurally complex process involving ionic, stereo-chemical, and structural interactions at the biomacromolecule-mineral interface. ${ }^{1}$ Natural biomineralization products have been the focus of materials scientists because of their unique properties. A lot of experiments have been designed and carried out to search for the possible formation mechanism of natural biominerals. ${ }^{2}$ The formation of calcium carbonate polymorphs, mainly calcite, aragonite and vaterite, has been reported in a number of cases such as gallstones, ${ }^{3}$ pancreatic stones in both humans and cattle, ${ }^{4}$ to animal phyla, algae, and in mollusk shells. ${ }^{5}$ It has been found that supersaturation is critical in determining the calcium carbonate polymorph precipitating. Thus, at high degrees of supersaturation, where spontaneous precipitation occurs, vaterite forms predominantly even at $25^{\circ} \mathrm{C}$. ${ }^{6}$ The organic matrices are considered to play a principal role in biominer-

\footnotetext{
*For correspondence
}

alization, but their function is still unclear. From literature it is known that carbohydrates have a minor influence, ${ }^{7}$ while proteins have a major effect ${ }^{8-10}$ on dissolution and precipitation of calcium phosphates.

BSA is widely used as matrix or soft template to induce the formation of calcium carbonate. $\mathrm{Xue}^{\mathrm{Z}} \mathrm{H}^{11}$ used BSA Langmuir film as a template to induce the formation of global calcite microcrystal. Zhang ${ }^{12}$ synthesized calcite under different concentrations of bovine serum albumin. Saccharides are one group of important polymers widely present in living organisms. Saccharide was also used as organic matrix to biomimetic crystallization of calcium carbonate. A novel aragonite ${ }^{13}\left(\mathrm{CaCO}_{3}\right)$ was synthesized with specific morphology by $\beta$-cyclodextrin. Glucan ${ }^{14}$ was used as a template to control synthesis of aragonite calcium carbonate.

This paper mainly discusses the cooperative influence of the sucrose/bovine serum albumin system which is close to biological organisms on calcium carbonate precipitation. The aim of these experiments is to find the effect on the polymorph and morphology of calcium carbonate by the sucrose/bovine serum albumin system.

\section{Experimental}

\subsection{Materials and apparatus}

The anhydrous calcium chloride $\left(\mathrm{CaCl}_{2}\right)$, sodium bicarbonate $\left(\mathrm{NaHCO}_{3}\right)$ and sucrose were analytically 

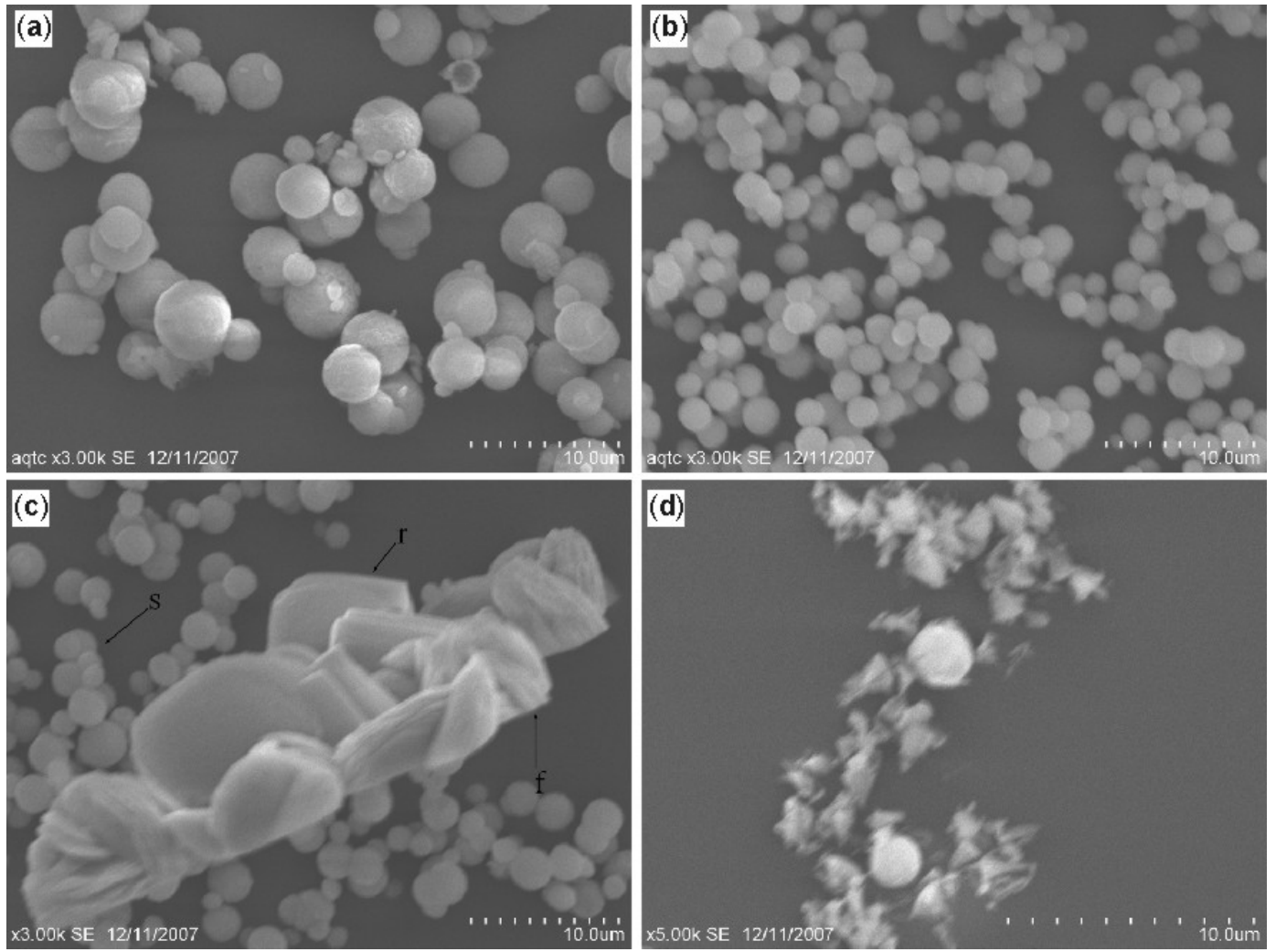

Figure 1. SEM of $\mathrm{CaCO}_{3}$ crystal obtained from the sucrose/bovine serum albumin system sucrose/BSA: (a) $5 \mathrm{wt} \% / 0$, (b) $5 \mathrm{wt} \% / 1 \times 10^{-6} \mathrm{~mol} \mathrm{~L}^{-1}$, (c) $5 \mathrm{wt} \% / 4 \times 10^{-6} \mathrm{~mol} \mathrm{~L}^{-1}$, (d) $20 \mathrm{wt} \% / 0$; in figure 1c: s (spherical), $\mathrm{r}$ (rhomboidal), $\mathrm{f}$ (filamentous).

pure. The bovine serum albumin were extra pure (more than 99\%), and purchased from Sigma Chemicals. All solutions were prepared with doubly deionized water. The sizes and morphologies of $\mathrm{CaCO}_{3}$ precipitates were characterized by using SEM on a DSM 940 A (Carl Zeiss, Jena) microscope. The specimen powders were prepared for SEM analysis by coating each with a thin gold/palladium layer to prevent specimen charging under the electron beam. Calibration of $\mathrm{CaCO}_{3}$ pellets (in a proportion of $1 \%$ in $\mathrm{KBr}$ powder) was performed and recorded with a Niolet 870 Fourier transform infrared spectrometer between 4000 and $400 \mathrm{~cm}^{-1}$ with a resolution of $4 \mathrm{~cm}^{-1}$. The XRD measurements were made by an MAP18XAHF X-ray diffractometry at a scanning rate of $1 \%$ min, using a monochromatized $\mathrm{CuK} \alpha$ radiation $(\lambda=0.154 \mathrm{~nm})$.

\subsection{Method of synthesizing $\mathrm{CaCO}_{3}$ crystals}

Calcium Carbonate was prepared according to the previously described methods. ${ }^{15} 0.84 \mathrm{~g}$ of anhydrous sodium carbonate $\left(\mathrm{Na}_{2} \mathrm{CO}_{3}\right)$ was placed at the bottom of a large beaker $(250 \mathrm{~mL})$, and $1.11 \mathrm{~g}$ of anhydrous calcium chloride $\left(\mathrm{CaCl}_{2}\right)$ was placed at the bottom of a small beaker $(100 \mathrm{~mL})$. The small beaker was placed in the large beaker. A series of the sucrose/bovine serum albumin solutions at different concentrations were added to the two beakers. The aqueous solution of the sucrose/bovine serum albumin was not added to the beaker until the solution surface exceeded the inner small beaker wall by 5-6 mm. The solution was kept at $25^{\circ} \mathrm{C}$ for 7 days without stirring. The sucrose/the bovine serum albumin concentration was $5 \mathrm{wt} \% / 0,5 \mathrm{wt} \% / 1 \times 10^{-6}$ $\mathrm{mol} \mathrm{L}{ }^{-1}, 5 \mathrm{wt} \% / 4 \times 10^{-6} \mathrm{~mol} \mathrm{~L}^{-1}$ and $20 \mathrm{wt} \% / 0$, respectively. When a large number of crystals were formed in the reaction vessel, the crystalline calcium carbonate was collected. The obtained crystalline $\mathrm{CaCO}_{3}$ was filtered through the solution and rinsed with distilled water and anhydrous alcohol at least five times, then centrifugalized, dried and collected.

\subsection{Powder X-ray diffraction, SEM and FT-IR analysis}

The obtained crystalline $\mathrm{CaCO}_{3}$ was collected for the determination of SEM, FT-IR and XRD. 


\section{Results and discussion}

3.1 Characterization of $\mathrm{CaCO}_{3}$ crystals produced in different concentrations of the sucrose/bovine serum albumin aqueous solutions

3.1a SEM images: Figure la-c showed SEM pictures of $\mathrm{CaCO}_{3}$ particles precipitated in sucrose solutions concentration $5 \mathrm{wt} \%$ and different concentrations bovine serum albumin. Well-dispersed spherical particles with smooth spherical surfaces were gained (figure la) in the system without bovine serum albumin. The particles size was $2-4 \mu \mathrm{m}$. When bovine serum albumin concentration $[\mathrm{BSA}]=1 \times 10^{-6}$ mol L ${ }^{-1}$, the well-dispersed spherical particles were still gained, which became smaller with size of $\sim 2 \mu \mathrm{m}$ (figure 1b). Surprisingly, when [BSA] was increased to $4 \times 10^{-6} \mathrm{~mol} \mathrm{~L}^{-1}$, some of the crystallites were spherical and some rhomboidal. Also seen are bundles of filamentous particles (figure 1c). Figure 1d showed the $\mathrm{CaCO}_{3}$ particles like catkin which formed in sucrose solution with concentration of $20 \mathrm{wt} \%$.

3.1b FT-IR spectra and XRD: Figure $2 \mathrm{a}-\mathrm{d}$ was the FT-IR spectra of $\mathrm{CaCO}_{3}$ crystals got from sucrose/ the bovine serum albumin system solutions with the concentrations of $5 \mathrm{wt} \% / 0,5 \mathrm{wt} \% / 1 \times 10^{-6} \mathrm{~mol} \mathrm{~L}^{-1}$, $5 \mathrm{wt} \% / 4 \times 10^{-6} \mathrm{~mol} \mathrm{~L}^{-1}$ and $20 \mathrm{wt} \% / 0$, respectively. Bands at 874 and $744 \mathrm{~cm}^{-1}$ indicated the formation of vaterite (figure $2 \mathrm{~b}-\mathrm{d}$ ). While in figure $2 \mathrm{a}$, simulta-

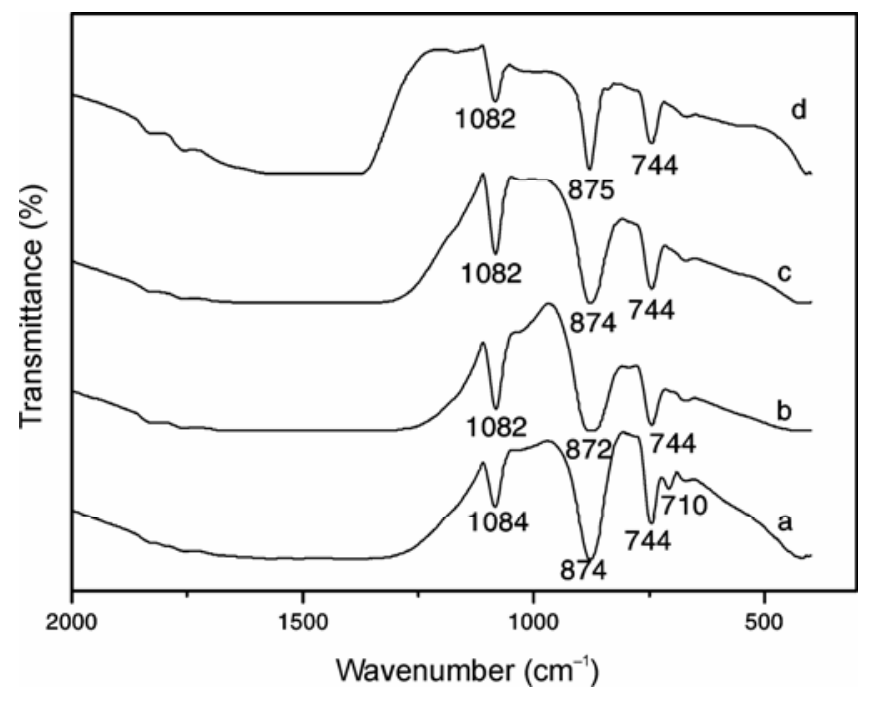

Figure 2. FT-IR spectra of $\mathrm{CaCO}_{3}$ crystal obtained from sucrose/BSA system, sucrose/BSA. (a) $5 \mathrm{wt} \% / 0$, (b) $5 \mathrm{wt} \% / 1 \times 10^{-6} \mathrm{~mol} \mathrm{~L}^{-1}$, (c) $5 \mathrm{wt} \% / 4 \times 10^{-6} \mathrm{~mol} \mathrm{~L}^{-1}$, (d) $20 \mathrm{wt} \% / 0$. neous occurrence of absorption peaks at 874,710 and $744 \mathrm{~cm}^{-1}$ indicated the presence of crystalline calcite and vaterite. ${ }^{16}$ There was little difference among figure $2 \mathrm{~b}-\mathrm{d}$ curves. The slight discrepancy between experimental and published IR values could be attributed to the required grinding of a $\mathrm{CaCO}_{3}$ sample with $\mathrm{KBr}$ to produce pellets. ${ }^{17}$ Figures $3 \mathrm{a}-\mathrm{d}$ showed the XRD patterns of $\mathrm{CaCO}_{3}$ particles obtained in sucrose/BSA system. Figure 3 a showed the $\mathrm{XRD}$ of $\mathrm{CaCO}_{3}$ particles formed in the system only with $5 \mathrm{wt} \%$ sucrose. Using the reflection peaks at (104) plane for calcite and (110) plane for vaterite, we can find that there are not only sharp calcite but vaterite reflections in figure $3 \mathrm{a}$, confirming that low concentration ( $5 \mathrm{wt} \%$ sucrose) led to the formation of calcite and vaterite. While high concentration (20 wt\% sucrose, figure 3d) led to the formation of vaterite. As figures $3 \mathrm{~b}-\mathrm{c}$ had shown, only the diffraction peaks from vaterite appeared, this provides further evidence for only the existence of vaterite in the products formed in sucrose/BSA solution. The XRD patterns of $\mathrm{CaCO}_{3}$ induced by $5 \mathrm{wt} \% / 1 \times$ $10^{-6} \mathrm{~mol} \mathrm{~L}^{-1}, \quad 5 \mathrm{wt} \% / 4 \times 10^{-6} \mathrm{~mol} \mathrm{~L}^{-1} \quad$ sucrose/BSA were similar to each other. The assignment of polymorphs to calcite or vaterite was carried out by comparison of literature data with their XRD patterns. ${ }^{18}$ Assuming that the specimen is a uniform mixture of two components and micro-absorption effects are neglected, it can be shown as equation (1) ${ }^{19}$

$$
\frac{I_{A}}{I_{B}}=\Lambda \times \frac{X_{A}}{X_{B}}
$$

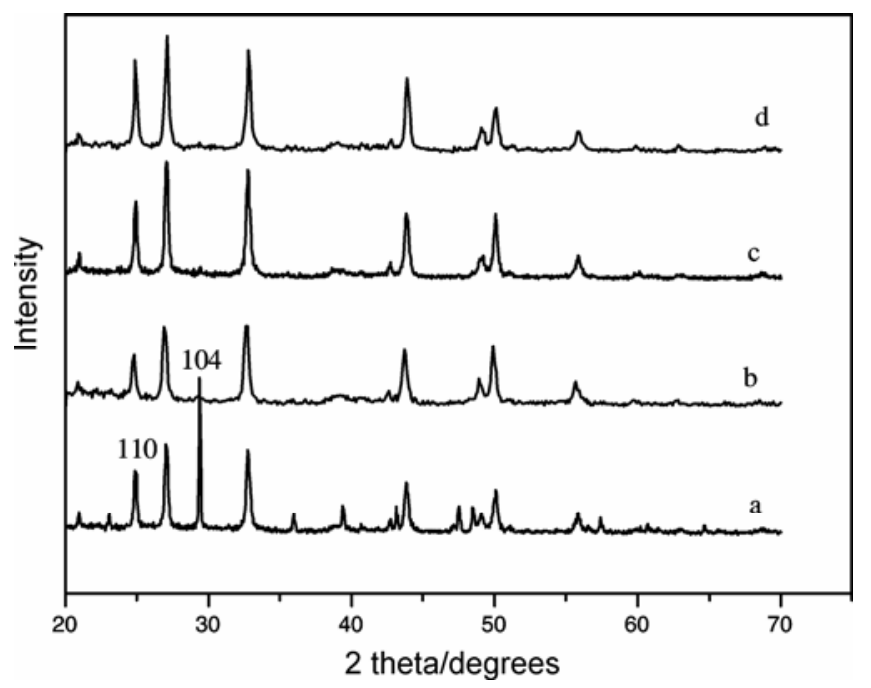

Figure 3. XRD patterns of $\mathrm{CaCO}_{3}$ crystal obtained from sucrose/BSA system, sucrose/BSA. (a) $5 \mathrm{wt} \% / 0$, (b) $5 \mathrm{wt} \% /$ $1 \times 10^{-6} \mathrm{~mol} \cdot \mathrm{L}^{-1}$, (c) $5 \mathrm{wt} \% / 4 \times 10^{-6} \mathrm{~mol} \mathrm{~L}{ }^{-1}$, (d) $20 \mathrm{wt} \% / 0$. 
where $\Lambda$ is a proportionality constant, which depends on the component, the diffraction line and the mass absorption coefficient of the species present. $I_{A} / I_{B}$ represents the ratio of the intensities of two selected diffraction lines in a mixture of two substances, and $X_{A} / X_{B}$ is the molar diffraction of the two substances. A plot of $I_{A} / I_{B}$ should yield a straight line with an intercept of zero. The calibration line for calcite-vaterite mixture was constructed. For the vaterite-calcite mixture the equation for the calibration line was obtained by linear regression of the experimental data, it can be described by the following relationship (2):

$$
\frac{I_{C}^{104}}{I_{V}^{10}}=7 \cdot 691 \times \frac{X_{C}}{X_{V}} .
$$

From figure $3 \mathrm{a}$ the intensity ratio $I_{(104)} / I_{(110)}$ were about $2 \cdot 4$, according to (2), we can calculate that the absolute contents of calcite as $23.5 \%$.

\subsection{The formation mechanism of $\mathrm{CaCO}_{3}$ crystal in the sucrose/ bovine serum albumin system}

The sucrose ring molecules (scheme 1) may be helpful to induce spherical calcium carbonate particles. With the addition of the BSA, protein-sucrose complexes were formed. At the same time, the process weakened the role of the sucrose; on the other hand, there was a strong coordination between BSA and $\mathrm{Ca}^{2+} \cdot \mathrm{Ca}^{2+}$ ions were attracted by oxygen atom of $\mathrm{C}=\mathrm{O}$ bond and the oxygen of hydroxyl from all directions in the system. Therefore the spherical morphology of $\mathrm{CaCO}_{3}$ could exist stably. With steric hindrance of the ring sucrose structure, more and more $\mathrm{Ca}^{2+}$ became free which made the formation of calcium carbonate toward the easy and stable direction. The special shape of calcium carbonate (figure 1c) might explain the possibility of the assumption. However, high concentrations of sucrose were not helpful to induce calcium carbonate particles with

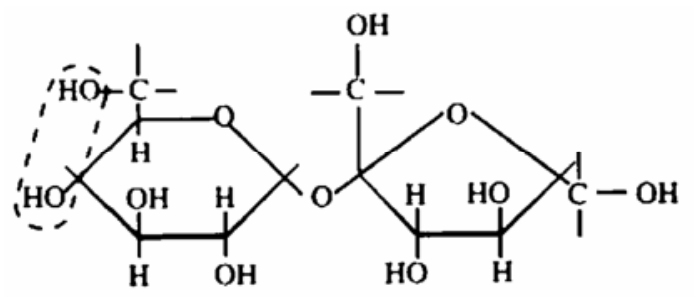

Scheme 1. Structure of sucrose regular morphology. The sucrose's viscosity might have limited the movement of $\mathrm{Ca}^{2+}$ in the system. The spherical calcium carbonate particles (figure 1d) would have disappeared when the concentration of sucrose was up to a certain amount.

During the formation of calcium carbonate, the nucleation and growth of the crystals might be affected by the sucrose/bovine serum albumin through electrostatic matching, structural and interfacial molecular recognition. The stereo-structure of the crystal nucleus was affected by this interfacial molecular recognition. And the activation energy of nucleation $\left(\Delta G^{*}\right)$ was decreased by interfacial molecular recognition. With the decrease of $\Delta G^{*}$, the vaterite has more easy formed and existed under this condition. ${ }^{20}$

\section{Conclusions}

In our investigation, an easy route nucleation model is employed in the nucleation of $\mathrm{CaCO}_{3}$ under the influence of sucrose/bovine serum albumin. The experimental results indicated that sucrose and sucrose/bovine serum albumin could direct the nucleation and crystallization of $\mathrm{CaCO}_{3}$. Sucrose tended to induce vaterite and calcite formation in the low concentration of sucrose, while the addition of bovine serum albumin led to the stable formation of vaterite. This research may provide new insights into the control of morphologies of $\mathrm{CaCO}_{3}$ and the controllable synthesis of novel inorganic materials.

\section{Acknowledgements}

Authors acknowledge the financial support provided by Natural Science Fund for colleges and universities in Anhui Province (No. KJ2008B173) for carrying out this work.

\section{References}

1. Murphy L W and Mooney J D $2002 \mathrm{~J}$. Am. Chem. Soc. 1241910

2. Po L, Qiang S and Ying Z 2004 Langmuir 2010444

3. Kanfman H S, Magnuson T H and Pitt H A 1994 Hepatology 191124

4. Moore E W and Verine H J $1987 \mathrm{~J}$. Am. Phys. Soc. 252 G707

5. Arends J 1982 Mechanism of dental caries In Biological mineralization and demineralization: Life sciences research report (ed.) Nancollas (Berlin: Springer-Verlag) 23 
6. Xyla A G, Microyannidis $\mathrm{J}$ and Koutsoukos PG 1992 J. Colloid Interface Sci. 153 537

7. Matsumoto T, Okazaki M and Taira M 2000 Caries Res. 3426

8. Shimabayashi S, Tanizawa Y K 1991 Ishida, Chem. Pharm. Bull. (Tokyo) 392183

9. Wassell D T, Hall R C and Embery G 1995 Biomaterials1 6697

10. Wen H B, de Wijn J R and van Blitterswijk C A 1999 J. Biomed. Mater. Res. 46245

11. Xue Zhong-Hui and Dai Shu-Xi 2006 Chinese J. Inorg. Chem. 221049

12. Zhang Q and Guan Y B 2007 Chinese J. Inorg. Chem. 23343
13. Xiu-Ying Zhang, Zhao-Jiang Liao and Lin Yang 2003 Acta Chimica Sinica 6169

14. Yang L, Ding W J and An Y G 2004 Chem. J. Chinese $U \mathbf{2 5} 1403$

15. Cheng-Li YAO 2008 Chin. J. Chem. 261075

16. Clarkson J R and Adams T J 1992 J. Chem. Soc. Faraday Trans. 88243

17. Loste E, Wilson R M, Seshadri R and Meldrum F C 2003 J. Cryst. Growth 254206

18. Porto S P S, Giordmaine J A and Damen T C 1966 Phys. Rev. 147608

19. An-Jian Xie, Chun-Yan Zhang and Yu-Hua Shen 2006 Cryst. Res. Technol. 41967

20. Lin Yang, Yuming Guo and Xiaoming Ma $2003 \mathrm{~J}$. Inorg. Biochem. 93197 